\title{
ANALISIS POTENSI PENGELOLAAN SAMPAH BERKELANJUTAN BERBASIS MASYARAKAT DI DESA SARIBAYE NUSA TENGGARA BARAT
}

\author{
Fati Ramadhanti \\ Universitas Prasetiya Mulya \\ Email: fati.ramadhanti@pmbs.ac.id
}

\section{ABSTRACT \\ ANALYSIS OF COMMUNITY BASED SUSTAINABLE WASTE MANAGEMENT IN DESA SARIBAYE WEST NUSA TENGGARA}

Tourism activities are more likely to bring positive impact on the economy of the society. However, if managed poorly, the tourism activities may also bring a bad luck to the region. One of the negative impacts is the excessive unmanaged waste. The excessive waste may create problems that harm the environment and affect the society well-being. This paper aims to examine the potential of sustainable waste management practice in tourism area in Lombok, West Nusa Tenggara. This paper also intent to specifically examine the potential of community participatory aspect in sustainable waste management. This research uses Participatory Rural Appraisal (PRA) methodology to assess the primary data. Additionally, further analysis of secondary data is also added. The research is conducted in tourism area in Saribaye village, Lingsar, West Nusa Tenggara province. The results show that Saribaye village residents still lack of enviromenment awareness and the infrastructure is still far from adequate to support a sustainable management practice. However, the Saribaye village community have a high willingness to learn about the sustainable waste management practice and their current demographic structures may support the sustainable waste management development in the village.

Keywords: Waste Management; Community Participation; Tourism; SWOT

\section{PENDAHULUAN}

Indonesia memiliki potensi pariwisata yang besar. Nusa Tenggara Barat (NTB) sebagai salah satu tujuan wisata di Indonesia yang populer dan juga memiliki Kawasan Ekonomi Khusus, mengalami pertumbuhan pengunjung yang signifikan dalam satu dekade terakhir. Menurut Badan Pusat Statistik NTB (BPS NTB, 2019), total wisatawan yang berkunjung ke NTB pada tahun 2009 yaitu 619.370 orang. Angka ini naik secara fantastis, hingga hampir $5 x$ lipat dalam kurun waktu 7 tahun, yaitu dengan jumlah pengunjung sebanyak 3.094.437 orang di tahun 2016. Memiliki potensi pariwisata yang besar, NTB ke depannya menghadapi tantangan untuk dapat mengelola sampah yang dihasilkan dari sektor pariwisata tersebut dengan lebih baik.

Di tahun 2018, provinsi NTB menghasilkan lebih dari 630 ton sampah per harinya. Tahun lalu, kota Mataram sebagai ibukota provinsi, sempat mengalami permasalahan sampah, dimana banyak timbunan sampah menggunung dan berserakan di tempat umum (SuaraNTB, 2018). Salah satu penyebabnya adalah karena minimnya anggaran pemerintah dalam penangangan sampah. Praktek pengelolaan sampah saat ini pun masih sangat konvensional dan prosesnya tidak terintegrasi satu sama lain. Dengan masalah sampah yang ada dan potensi produksi sampah yang kian 
meningkat seiring meningkatnya aktivitas pariwisata dan ekonomi di NTB, permasalahan pengelolaan sampah ini perlu segera ditangani.

Saat ini tren global dalam pengelolaan destinasi pariwisata adalah dengan menggunakan konsep Pariwisata Berkelanjutan atau Sustainable Tourism. Konsep ini juga sudah diadopsi oleh Kementerian Pariwisata Indonesia yaitu dalam Peraturan Menteri Pariwisata no. 14 tahun 2016 mengenai Pedoman Destinasi Pariwisata Berkelanjutan. Dalam mengembangkan destinasi pariwisata, Pariwisata Berkelanjutan (PB) tidak hanya mengedepankan aspek ekonomi, namun juga aspek lingkungan, aspek sosial, dan juga aspek budaya (World Tourism Organization, 2004). Saat ini konsep PB sudah banyak diterapkan dibanyak negara terutama di negara maju seperti negara-negara di Eropa, Amerika dan Australia (Lu \& Nepal, 2009). Konsep dari PB juga sejalan dengan visi dan misi Pemerintah baik oleh Pemerintah Pusat, maupun Pemerintah Daerah NTB.

Salah satu aspek yang penting dalam PB adalah adanya sistem pengelolaan sampah yang baik. Pengelolaan sampah yang dilakukan di provinsi NTB saat ini adalah pengelolaan sampah secara konvensional dan tidak terintegrasi. Bahkan, di beberapa daerah di NTB, sarana/prasarana pembuangan sampah seperti TPS atau TPA masih tidak tersedia. Untuk menghadapi laju tumbuh sektor pariwisata, Pemerintah Daerah NTB harus bisa mengelola sampahnya dengan lebih baik, salah satunya dengan melakukan pengelolaan sampah yang berkelanjutan. Pengelolaan Sampah yang Berkelanjutan (PSB) atau Sustainable Waste Management mulai banyak diterapkan di Asia (Visvanathan et al., 2007). Di dalam negeri sendiri, beberapa penelitian juga sudah mengungkapkan pentingnya sistem PSB dalam pengelolaan dan pelestarian daerah pariwisata (Dewi, 2017; Vitasurya, 2017).

PSB adalah suatu proses dimana pengelolaan sampah sudah lebih terintegrasi satu sama lain dan memiliki keterlibatan pemangku kepentingan (stakeholder) yang lebih luas (Rodic et al., 2010). Rodic et al
(2010) lebih lanjut lagi menyebutkan tiga aspek utama dalam PSB adalah aspek fisik/teknikal, aspek keberlanjutan, dan aspek pelaku (formal dan informal) dalam sistem tersebut. Pada saat ini, integrasi pada sistem pengelolaan sampah di berbagai desa di Indonesia masih lemah (Artiningsih et al., 2012; Setiadi, 2015; Utami et al., 2008). Pengelolaan sampah diberbagai daerah masih dilakukan secara tradisional dan tidak mengimplementasikan sistem yang terintegrasi, dimana proses munculnya sampah, pengambilan sampah, dan pembuangan sampah masih dilakukan secara terpisah. Dengan menerapkan pengelolaan sampah yang berkelanjutan, banyak manfaat yang akan didapatkan oleh masyarakat, terutama dari sisi lingkungan dan kesehatan publik (Joseph, 2006).

Dalam menelaah potensi PSB, paper ini akan fokus membahas aspek informal stakeholders dan juga infrastruktur yang ada di Desa Saribaye. Informal stakeholder yang dimaksud adalah masyarakat Desa Saribaye secara keseluruhan. Informal stakeholder dipilih karena dalam mewujudkan suatu pengelolaan sampah yang berkelanjutan, peran masyarakat sangat penting dan dibutuhkan. Pengelolaan sampah dengan melibatkan masyarakat biasa disebut dengan pengelolaan sampah berbasis masyarakat. Pendekatan yang digunakan adalah pendekatan bottom-up dimana dalam proses pelaksanaan suatu kegiatan di suatu lokasi, masyarakat lokal berperan secara aktif dalam mengidentifikasi masalah, mengambil keputusan, serta merancang solusi untuk masalah tersebut (World Health Organization, 2002). Pengelolaan sampah dengan konsep parsitipasi masyarakat/komunitas juga sedang marak berkembang di Indonesia (Putri et al., 2012; Setiadi, 2015). Keterlibatan masyarakat dalam kegiatan pengelolaan sampah dapat menghasilkan pengelolaan sampah yang mandiri. Putri et al. (2012) dalam penelitiannya di Komunitas Adat Seminyak Bali menunjukkan bahwa dengan pendekatan yang dilakukan secara bottom-up (partisipasi masyarakat), peran serta masyarakat dalam pengelolaan tersebut mencapai lebih dari $70 \%$. 
Manfaat dari kegiatan PSB dengan berbasis masyarakat diharapkan tidak hanya mengurangi dampak negatif di lingkungan, tetapi juga dapat memberikan keuntungan materi bagi masyarakat lokal dari hasil penjualan sampah plastik atau hasil produk daur ulang. Dengan melakukan pengelolaan sampah yang berkelanjutan, suatu destinasi wisata juga dapat mengurangi masalah sampah lokal, menekan biaya pengangkutan sampah, dan dapat menambah nilai keunikan untuk daerah destinasi wisata.

\section{METODOLOGI}

Lokasi kajian potensi penerapan pengelolaan sampah berkelanjutan dilakukan di Desa Saribaye, Lingsar, Kabupaten Lombok Barat. Desa Saribaye dipilih karena merupakan salah satu daerah destinasi wisata di Lombok. Desa Saribaye saat ini belum memiliki pengelolaan sampah. Berlokasi di bantaran Sungai Jangkok, Desa Saribaye juga merupakan salah satu penyumbang pada pencemaran/polusi sampah di perairan Lombok.

\subsection{Pertanyaan Riset}

Dalam penelitian ini, ada beberapa pertanyaan riset yang sudah diformulasikan:

1. Apakah masyarakat Desa Saribaye memiliki kesadaran lingkungan yang baik?

2. Apakah masyarakat Desa Saribaye memiliki kemauan dalam melakukan pengelolaan sampah berbasis masyarakat?

3. Apakah Desa Saribaye memiliki sarana/prasarana yang memadai untuk melakukan pengelolaan sampah?

4. Apakah ada potensi untuk Desa Saribaye untuk dapat melakukan pengelolaan sampah yang berkelanjutan berbasis masyarakat?

\subsection{Pengambilan Data}

\subsubsection{Data Primer: Participatory Rural Appraisal (PRA)}

Pendekatan yang di lakukan untuk mendapatkan data primer adalah dengan
Participatory Rural Appraisal (PRA). PRA atau juga disebut Pemahaman Partisipatif Kondisi Pedesaan (PPKP) adalah pendekatan yang melibatkan masyarakat secara langsung dalam merumuskan rencana tindakan dan kebijakan. Metode PRA dipilih karena memungkinkan masyarakat desa untuk saling berbagi dan menganalisis pengetahuan masyarakat, dan membuat rencana dan tindakan nyata (Chambers, 1994).

Dalam penelitian ini, metode atau tools PRA yang digunakan secara spesifik adalah dengan Focus Group Discussion (FGD). Peneliti juga melakukan observasi sebagai bentuk triangulasi kebenaran/validasi data primer yang diambil. Pengambilan data primer dilakukan pada bulan Agustus 2018. Dalam FGD ini peserta diberikan pertanyaan menyangkut kesadaran lingkungan, kemauan untuk melakukan pengelolaan sampah, dan mengenai sarana dan prasarana pengelolaan sampah yang tersedia. FGD ini ditargetkan pada 4 kelompok, yaitu:

1. Kelompok Ibu Rumah Tangga,

2. Kelompok Petani,

3. Kelompok Bisnis/Pengusaha, dan

4. Kelompok Pemuda

\subsubsection{Data Sekunder}

Data sekunder yang digunakan adalah data demografi kependudukan Desa Saribaye yang didapatkan dari Kantor Desa. Faktor demografi adalah salah satu hal yang penting dalam melihat potensi dalam pengelolaan sampah (Rodic et al., 2010). Adapun data yang dikaji adalah luas wilayah, populasi, tingkat pendidikan, tingkat kesejahteraan dan mata pencaharian dari penduduk Desa Saribaye.

\subsection{Metode Analisis Data}

Analisis data dilakukan dengan meninjau data primer yang didapatkan dari FGD serta data sekunder yang didapatkan dari Kantor Desa. Selanjutnya data primer dan sekunder tersebut dianalisis dalam empat kategori, yaitu:

1. Analisis perilaku masyarakat dalam pengelolaan sampah yaitu aspek kesadaran lingkungan dan kemauan 
dalam pengelolaan sampah menggunakan data primer

2. Analisis sistem sarana dan prasarana pendukung pengelolaan sampah menggunakan data primer

3. Analisis demografi dengan menggunakan data sekunder

4. Analisis SWOT untuk melihat potensi pengelolaan sampah berkelanjutan menggunakan data primer dan data sekunder

\section{HASIL DAN PEMBAHASAN}

\subsection{Hasil FGD}

Penelitian ini meninjau perilaku berdasarkan tingkat kesadaran lingkungan dan kemauan masyarakat Desa Saribaye dalam mengelola sampah. Tema tersebut kemudian ditentukan dalam beberapa aspek yang digunakan untuk meninjau perilaku masyarakat (lihat Tabel 1).

Tabel 1. Tema dan Aspek yang Ditinjau dalam FGD

\begin{tabular}{lll}
\hline No. & \multicolumn{1}{c}{ Tema } & \multicolumn{2}{c}{ Aspek yang Ditinjau } \\
\hline 1. & Kesadaran Lingkungan & - Pengetahuan jenis-jenis sampah yang dihasilkan \\
& & - Pengetahuan dampak sampah terhadap lingkungan \\
& - Praktik pembuangan sampah sehari-hari \\
2. & $\begin{array}{l}\text { Kemauan mengelola } \\
\text { sampah }\end{array}$ & - Komitmen mengurangi sampah \\
3. & Sarana dan prasarana \\
& pengelolaan sampah di \\
Desa Saribaye & - Pengetahuan ketersediaan fasilitas pengelolaan sampah di \\
\end{tabular}

Dengan menggunakan aspek penijauan pada Tabel 1, maka didapatkan hasil FGD data perilaku masyarakat Desa Saribaye, pengetahuan tentang sarana dan prasarana serta pengelolaan sampah di Desa, seperti tercantum pada Tabel 2.

Tabel 2. Hasil FGD Prilaku lingkungan masyarakat Desa Saribaye

\begin{tabular}{|c|c|c|c|}
\hline No. & $\begin{array}{l}\text { Kelompok } \\
\text { FGD }\end{array}$ & $\begin{array}{l}\text { Aspek yang } \\
\text { ditinjau }\end{array}$ & Hasil \\
\hline \multirow[t]{3}{*}{1.} & \multirow[t]{3}{*}{$\begin{array}{l}\text { Ibu Rumah } \\
\text { Tangga } \\
\text { (IRT) }\end{array}$} & $\begin{array}{l}\text { Kesadaran } \\
\text { Lingkungan }\end{array}$ & $\begin{array}{l}\text { - IRT mengetahui jenis sampah sampah organik } \\
\text { dapur dan sampah plastik kemasan } \\
\text { - IRT menyebutkan bahwa dampak dari sampah } \\
\text { plastik dapat menimbulkan penyakit, dan jika } \\
\text { dibakar, bisa menyebabkan kanker. } \\
\text { - IRT dalam praktiknya mengelola sampah sehari- } \\
\text { hari dengan dibakar dan dibuang ke sungai. }\end{array}$ \\
\hline & & $\begin{array}{l}\text { Kemauan } \\
\text { Pengelolaan } \\
\text { Sampah }\end{array}$ & $\begin{array}{l}\text { - IRT ingin mengurangi jumlah sampah namun } \\
\text { tidak mengetahui caranya }\end{array}$ \\
\hline & & Sarana/Prasarana & $\begin{array}{l}\text { - Sampah plastik yang bernilai dijual di bank } \\
\text { sampah My Darling } \\
\text { - IRT bertanggung jawab dalam membuang } \\
\text { sampah hasil rumah tangga. }\end{array}$ \\
\hline
\end{tabular}




\begin{tabular}{|c|c|c|c|}
\hline No. & $\begin{array}{l}\text { Kelompok } \\
\text { FGD }\end{array}$ & $\begin{array}{l}\text { Aspek yang } \\
\text { ditinjau }\end{array}$ & Hasil \\
\hline \multirow[t]{3}{*}{2.} & \multirow[t]{3}{*}{ Petani } & $\begin{array}{l}\text { Kesadaran } \\
\text { Lingkungan }\end{array}$ & $\begin{array}{l}\text { - Petani dapat mengidentifikasi sampah seperti } \\
\text { sampah plastik, kotoran sapi, dan sisa pertanian } \\
\text { - Sampah yang dihasilkan sebagian dibakar dan } \\
\text { sebagian lain dibuang ke sungai } \\
\text { - Petani sadar bahwa sampah plastik dapet } \\
\text { menimbulkan penyakit }\end{array}$ \\
\hline & & $\begin{array}{l}\text { Kemauan } \\
\text { Pengelolaan } \\
\text { Sampah }\end{array}$ & $\begin{array}{l}\text { Petani memiliki kemauan untuk melakukan } \\
\text { pengelolaan sampah, namun tergantung dari } \\
\text { besarnya insentif ekonomi yang diterima }\end{array}$ \\
\hline & & Sarana/Prasarana & $\begin{array}{l}\text { - Petani menyadari ada bank sampah My Darling di } \\
\text { Desa Saribaye, tetapi belum bergabung menjadi } \\
\text { nasabah. }\end{array}$ \\
\hline \multirow[t]{3}{*}{3.} & \multirow[t]{3}{*}{ Pengusaha } & $\begin{array}{l}\text { Kesadaran } \\
\text { Lingkungan }\end{array}$ &  \\
\hline & & $\begin{array}{l}\text { Kemauan } \\
\text { Pengelolaan } \\
\text { Sampah }\end{array}$ & $\begin{array}{l}\text { - Pengusaha ingin mengelola sampah jika } \\
\text { disediakan fasilitas oleh pemerintah }\end{array}$ \\
\hline & & Sarana/Prasarana & $\begin{array}{l}\text { - Pengusaha memanfaatkan jasa bank sampah My } \\
\text { Darling }\end{array}$ \\
\hline \multirow[t]{3}{*}{4.} & \multirow[t]{3}{*}{ Pemuda } & $\begin{array}{l}\text { Kesadaran } \\
\text { Lingkungan }\end{array}$ & $\begin{array}{l}\text { - Pemuda dapat mengidentifikasi jenis-jenis } \\
\text { sampah berdasarkan aktivitas masyarakat yang } \\
\text { ada di desa. } \\
\text { - Pemuda memahami dampak sampah terhadap } \\
\text { kesehatan, potensinya menjadi sarang nyamuk, } \\
\text { dan bisa menyebabkan banjir. }\end{array}$ \\
\hline & & $\begin{array}{l}\text { Kemauan } \\
\text { Pengelolaan } \\
\text { Sampah }\end{array}$ & $\begin{array}{l}\text { - Pemuda menginisiasi bank sampah My Darling } \\
\text { untuk mengelola sampah plastik. }\end{array}$ \\
\hline & & Sarana/Prasarana & $\begin{array}{l}\text { - Fasilitas yang ada saat ini terbatas pada } \\
\text { pengumpulan sampah plastik yang dilakukan } \\
\text { bank sampah My Darling. } \\
\text { - Tidak ada fasilitas pengelolaan sampah. }\end{array}$ \\
\hline
\end{tabular}




\subsection{Hasil Data Sekunder}

A. Letak dan Luas Wilayah

Desa Saribaye terletak di kecamatan Lingsar, kabupaten Lombok Barat, Provinsi Nusa Tenggara Barat. Luar wilayah dari Desa Saribaye adalah 131,43 ha dengan luas pemukiman sekitar 80 ha, persawahan 82,3 ha, perkebunan 28.6 ha dan sisanya adalah perkantoran dan prasarana umum. Dengan luas persawahan yang besar, Desa Saribaye menjadi salah satu desa yang indah dan menarik untuk dikunjungi berwisata alam. Menjadi salah satu desa tujuan wisata di Lombok, Desa Saribaye belum memiliki fasilitas pengelolaan sampah yang memadai. Faktanya, mayoritas dari penduduk desa masih membuang sampah rumah tangga mereka di tahan kosong atau sungai/kali terdekat.

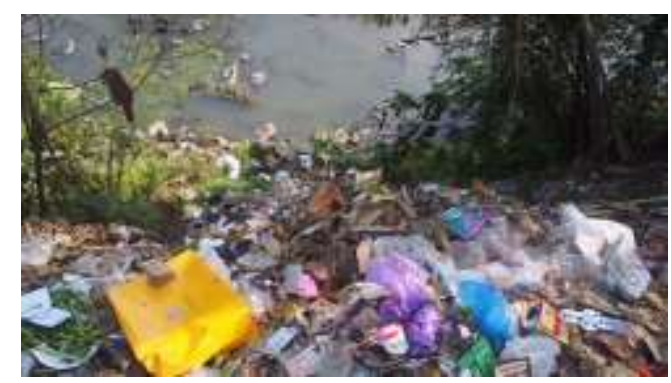

Gambar 1. Bantaran Sungai Jangkok menjadi Lokasi Pembuangan Sampah di Desa Saribaye

\section{B. Populasi}

Populasi di Desa Saribaye, berdasarkan Data Internal Kantor Administrasi Desa Saribaye yang tercatat pada tahun 2017, jumlah penduduk mencapai 2.294 orang dengan jumlah wanita sebanyak 1.126 orang dan pria sebanyak 1.168 orang. Dari total 2.294 orang, 1.731 orang atau sekitar $75 \%$ dari total tersebut adalah penduduk dalam usia produktif. Berdasarkan Badan Pusat Statistik (BPS, 2019), penduduk usia produktif sendiri adalah penduduk yang memiliki usia diantara $15-64$ tahun. Angka ini mengindikasikan bahwa Desa Saribaye memiliki potensi produktivitas sumber daya manusia yang besar.

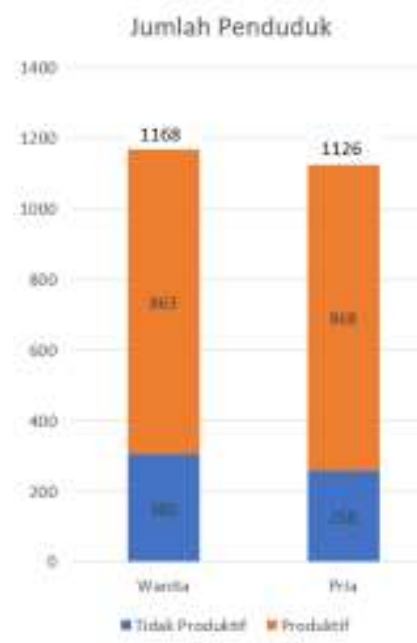

Gambar 2. Jumlah Penduduk Desa Saribaye berdasarkan Jenis Kelamin

\section{Pendidikan}

Berdasarkan latar belakang Pendidikan, sekitar $70 \%$ penduduk di Desa Saribaye pernah/sedang menempuh jenjang pendidikan. Angka ini menunjukkan kualitas sumber daya manusia yang relatif tinggi di Desa Saribaye.

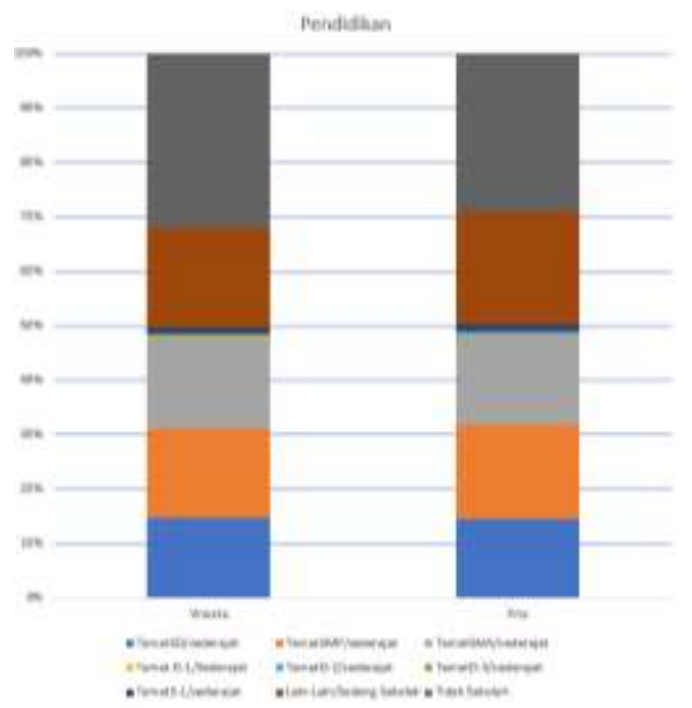

Gambar 3. Distribusi Pendidikan di Desa Saribaye 
D. Tingkat Kesejahteraan

Berdasarkan BKKBN (2019), tingkat kesejahteraan keluarga diklasifikasikan menjadi 5 kelompok, yaitu sebagai berikut:

i. Keluarga Prasejahtera

Adalah keluarga yang belum mampu memenuhi kebutuhan dasarnya berupa kebutuhan agaman, pangan, sandang dan kesehatan.

\section{ii. Keluarga Sejahtera 1}

Adalah keluarga yang telah mampu memenuhi kebutuhan dasar namun belum mampu memenuhi kebutuhan social psikologisnya.

iii. Keluarga Sejahtera 2

Adalah keluarga yang sudah mampu memenuhi kebutuhan dasar dan social psikologisnya, namun belum mampu memenuhi kebutuhan pengembangannya, seperti menabung dan memperoleh informasi.

iv. Keluarga Sejahtera 3

Adalah keluarga yang mampu memnuhi kebutuhan dasar, social psikologis dan kebutuhan pengembangannya, namun belum mampu untuk memberikan sumbangan maksimal kepada masyarakat.

v. Keluarga Sejahtera 3+

Adalah keluarga yang telah mampu memenuhi seluruh kebutuhannya, yaitu kebutuhan dasar, sosial psikologis, pengembangan dan dapat memberikan sumbangan maksimal kepada masyarakat.

Berdasarkan Data Internal Kantor Administrasi Desa Saribaye (2017) distribusi kesejahteraan keluarga di Desa Saribaye adalah sebagai berikut:

Tabel 3. Distribusi Kesejahteraan Keluarga di Desa Saribaye

\begin{tabular}{llc}
\hline No. & Kelompok Keluarga & Jumlah KK \\
\hline 1. & Keluarga Prasejahtera & $101 \mathrm{KK}$ \\
\hline 2. & Keluarga Sejahtera 1 & $70 \mathrm{KK}$ \\
\hline 3. & Keluarga Sejahtera 2 & $375 \mathrm{KK}$ \\
\hline 4. & Keluarga Sejahtera 3 & $190 \mathrm{KK}$ \\
\hline 5. & Keluarga Sejahtera 3+ & $0 \mathrm{KK}$ \\
\hline \multicolumn{2}{l}{ Total KK } & $736 \mathrm{KK}$ \\
\hline & Dari tabel diatas, jumlah kepala
\end{tabular}
keluarga yang masih termasuk keluarga prasejahtera adalah sejumlah $101 \mathrm{KK}$ atau sekitar 14\% dari total 736 KK di Desa Saribaye. Sedangkan untuk Keluarga Sejahtera 1, 2 dan 3, jumlah KK yang termasuk kelompok tersebut adalah $70 \mathrm{KK}$, 375 KK dan 190 KK, secara berurutan. Di Desa Saribaye, tidak ada satupun keluarga yang termasuk dalam Keluarga Sejahtera 3+.

\section{E. Mata Pencaharian}

Memiliki persawahan yang sangat luas, mayoritas penduduk di Desa Saribaye bekerja sebagai Petani dan Buruh Tani. Selain itu, untuk wanita, mayoritas penduduk adalah sebagai ibu rumah tangga, seperti yang telah ditampilkan pada Gambar 4 dibawah. Pengelolaan sampah berbasis masyarakat dapat menjadi suatu kegiatan yang dapat dimanfaatkan bagi penduduk yang belum bekerja ataupun para ibu rumah tangga untuk menyalurkan energi, ide dan kreatifitas, yang juga akan berdampak baik bagi keasrian dan kesehatan masyarakat disekitar lingkungan tersebut. 


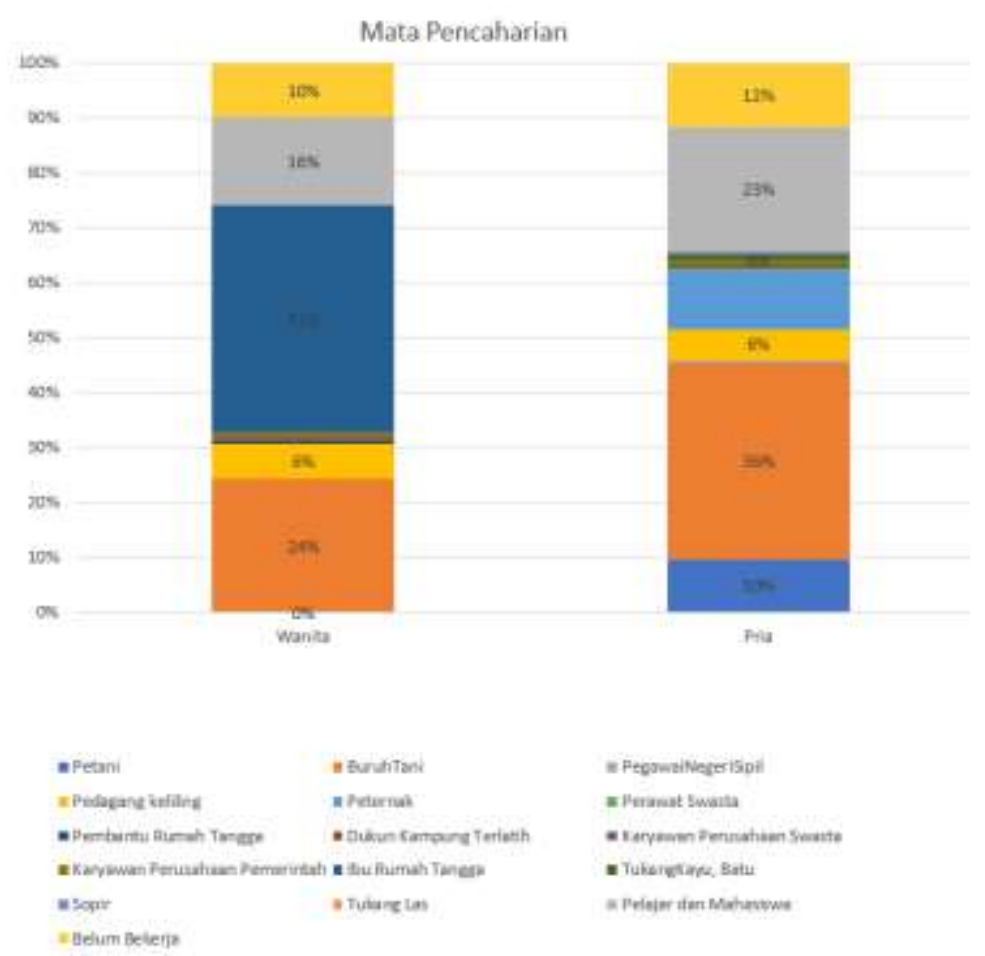

Gambar 4. Distribusi Mata Pencaharian Penduduk di Desa Saribaye

\subsection{Analisis Perilaku Masyarakat dalam Pengelolaan Sampah}

Dari hasil FGD (Tabel 2) diketahui bahwa di dalam pengelolaan sampah Desa Saribaye, masyakat masih membuang sampah tidak pada tempat pembuangan sampah. Masyarakat mengelola sampah rumah tangga secara individu dan tidak ada sistem pengelolaan yang tersedia dari pemerintah desa maupun dinas lingkungan hidup. Hasil FGD menunjukkan bahwa masyarakat membuang sampah di tempat-tempat terbuka yang dekat dengan lokasi tempat tinggal mereka. Sebagian besar warga membuang sampah di Sungai Jangkok yang mengalir melalui Desa Saribaye. Alasan warga membuang di bantaran sungai adalah karena tidak tersedianya fasilitas pembuangan sampah yang mudah dijangkau di Desa, dan sungai merupakan lahan kosong yang terdekat.

Sementara itu, masyarakat sebenarnya mengetahui bahwa membuang sampah di sungai dapat merusak lingkungan. Keempat kelompok masyarakat sebagian besar sudah mengetahui dampak dari masalah sampah di desa. Masyarakat juga sudah mengerti bahwa permasalahan sampah adalah tanggung jawab mereka semua. Lebih lanjut lagi, mengacu pada pernyataan Ibu-Ibu Rumah Tangga, aktivitas pembuangan sampah pada praktiknya lebih banyak dibebankan pada kaum perempuan, yaitu mereka sebagai Ibu Rumah Tangga.

Dengan demikian, pada saat ini masyarakat belum bisa dikatakan sebagai masyarakat yang sadar lingkungan, karena pengetahuan tersebut tidak sejalan dengan tindakan yang dilakukan warga dalam mengelola sampah yang mereka hasilkan. Prilaku sadar namun tidak sadar lingkungan bisa terjadi ketika masyarakat sendiri tidak melihat adanya insentif dalam mengubah kebiasaan mereka tersebut.

Di sisi lain, meskipun belum memiliki kesadaran lingkungan, masyarakat desa sadar akan pentingnya pengelolaan sampah dan memiliki keinginan untuk melakukan pengelolaan sampah di Desa Saribaye. Hal ini terbukti dengan adanya kelompok swadaya yang didirikan oleh masyarakat setempat khususnya para pemuda, yaitu Bank Sampah My Darling (Masyarakat Sadar Lingkungan). Berdasarkan hasil FGD, semua kelompok responden mengetahui akan keberadaan Bank Sampah My Darling, walaupun belum semua bergabung menjadi nasabah. Beberapa kelompok belum mengetahui bagaimana cara mengelola sampah yang baik secara mandiri. 
Untuk itu, mereka mengharapkan ada satu kegiatan yang bisa membantu mereka mengelola sampah, sekaligus juga bisa memberikan insentif ekonomi kepada masyarakat.

\subsection{Analisis Sistem Sarana dan Prasarana Pendukung Pengelolaan Sampah}

Hasil FGD menunjukkan bahwa belum tersedianya sarana pengelolaan sampah yang memadai di Desa Saribaye, seperti kontainer sampah ataupun Tempat Pembuangan Sementara (TPS) sehingga praktik membuang di lahan terbuka/sungai masih sangat sering dilakukan. Satu-satunya bentuk sarana/prasarana yang tersedia adalah sebuah komunitas swadaya masyarakat yaitu Bank Sampah My Darling (Masyarakat Sadar Lingkungan).

Manajemen Bank Sampah My Darling dilakukan secara swadaya oleh pemuda desa setempat. Bank Sampah My Darling mengumpulkan sampah plastik yang dipilah dari rumah nasabah untuk kemudian dijual kepada pengepul. Waktu operasi pengumpulan sampah plastik sangat terbatas, yaitu hanya sekali dalam seminggu. Dengan jumlah anggota sekitar 20 orang pemuda desa, bank sampah tidak mampu menjangkau seluruh wilayah Desa Saribaye untuk menjadi nasabahnya. Bank Sampah My Darling membiayai operasionalnya secara mandiri melalui iuran yang dikeluarkan oleh masingmasing anggotanya. Selain itu, operasional bank sampah juga didapatkan dari hasil penjualan sampah di pengepul, dan terkadang ditambah dengan dana bantuan dari desa.

Pengelolaan sampah Desa Saribaye belum memadai jika hanya bergantung pada Bank Sampah My Darling. Dengan kapasitas yang dimiliki bank sampah saat ini tidak akan mampu mengelola sampah yang dihasilkan warga desa. Padahal, jika melihat jumlah sampah yang dihasilkan satu rumah tangga, maka kemungkinan jumlah sampah yang dibuang tanpa diolah sangat besar. Berdasarkan Data Internal dari Kantor Administrasi Desa Saribaye, jumlah nasabah yang dikelola oleh Bank Sampah My Darling saat ini adalah $99 \mathrm{KK}$, sehingga masih banyak potensi dari grup swadaya ini untuk berkembang. Proses pengangkutan dan sudah dimulainya kebiasaan masyarakat dalam mengumpulkan dan memilah sampah ini, menunjukkan awal mula yang baik untuk mewujudkan terciptanya proses pengelolaan sampah yang berkelanjutan (Wilson, 2007).

\subsection{Analisis Data Demografi}

Berikut adalah hasil analisis data demografi dari Desa Saribaye dari segi Luas Wilayah, Populasi, Pendidikan, Kesejahteraan dan Mata Pencaharian:

- Potensi pariwisata dan luas wilayah Desa Saribaye mendukung untuk melakukan proses pengeloaan sampah berbasis masyarakat

- Jumlah usia produktif di Desa Saribaye yang besar mengindikasikan potensi sumber daya manusia yang besar untuk menjalankan pengelolaan sampah berbasis msayarakat

- Tingginya jumlah penduduk yang telah/sedang bersekolah memberikan peluang baik dalam berkomunikasi dengan masyarakat setempat sehingga dapat memberikan kemudahan dalam proses inisiasi dan keberlanjutan program (Riswan et al., 2011).

- Masih besarnya jumlah keluarga prasejahtera memberikan peluang bagi kegiatan pengelolaan sampah berbasis masyarakat ini untuk dapat menghasilkan suatu pendapatan tambahan yang diharapkan dapat meningkatkan kesejahteraan penduduk dan menekan angka kemiskinan.

- Dari segi mata pencaharian, jumlah kelompok penduduk yang belum bekerja dan jumlah kelompok ibu rumah tangga masih besar. Kegiatan pengelolaan sampah berbasis masyarakat dapat menjadi suatu sarana meningkatkan produktivitas dan kreatifitas penduduk untuk kelompok-kelompok tersebut.

Berdasarkan hasil analisis data demografi tersebut, Desa Saribaye memiliki potensi yang baik untuk mengimplementasikan program pengelolaan sampah berbasis masyarakat. 


\subsection{Analisis SWOT (Strength, Weakness, Opportunity, and Threat)}

Berdasarkan dari hasil FGD dan hasil data sekunder, berikut adalah hasil dari analisis SWOT:

1. Strengths
a. Kemauan yang besar dalam mengelola sampah
b. Adanya komunitas bank sampah "My Darling" yang sudah terbentuk dari swadaya masyarakat lokal

2. Weaknesses
a. Kesadaran lingkungan yang rendah
b. Sarana dan Prasarana serta proses pengelolaan sampah yang tidak memadai

3. Opportunities
a. Jumlah penduduk produktif yang besar dan potensi demografi yang memadai
b. Potensi ekonomi yang besar dari proses pengelolaan sampah berkelanjutan
c. Kegiatan pengelolaan sampah yang berkelanjutan dapat menjadi daya tarik wisata, serta hasil produk yang unik bisa menjadi ciri khas desa.

4. Threats
a. Tantangan dalam mengubah kebiasaan masyarakat
b. Pasar dari produk daur ulang yang masih berkembang

\section{SIMPULAN DAN SARAN}

\subsection{Kesimpulan}

Berdasarkan dari hasil penelitian dan analisis dari berbagai sisi dan sudut pandang serta menjawab pertanyaan riset sebelumnya, dapat disebutkan bahwa:

1. Mayoritas warga Saribaye sudah mengerti mengenai dampak buruk dari sampah, namun belum mengamalkan pengetahuan tersebut dikehidupan sehari-hari sehingga masih dapat dikatakan belum memiliki kesadaran lingkungan.

2. Warga Saribaye memiliki kemauan untuk mengelola sampah, namun masih terbatas oleh sarana dan prasarana yang tersedia.
3. Desa Saribaye memiliki jumlah penduduk usia produktif yang besar serta faktor demografi lain yang dapat mendukung terlaksananya kegiatan pengelolaan sampah yang berkelanjutan berbasis masyarakat.

4. Infrastruktur desa untuk pengelolaan sampah tidak memadai, namun ada potensi yang yang baik dari itikad sebagian warga untuk mengelola sampah plastik secara swadaya, yaitu kelompok Masyarakat Sadar Lingkungan "My DarLing". Hal ini menunjukkan potensi yang baik untuk melakukan suatu pengelolaan sampah berbasis masyarakat.

Sehingga disimpulkan bahwa Desa Saribaye memiliki potensi untuk melakukan pengelolaan sampah berkelanjutan berbasis masyarakat apabila didukung dengan kegiatan yang dapat meningkatkan kesadaran lingkungan serta dukungan pemerintah dalam bentuk infrastruktur dan prasaran pengelolaan sampah yang lebih baik dan memadai.

\subsection{Saran}

1. Perlu diadakannya suatu kegiatan edukasi dan workshop yang dapat meningkatkan pengetahuan serta kesadaran lingkungan masyarakat sehingga masyarakat tidak hanya mengetahui tapi juga menjalankan kegiatan-kegiatan yang dapat melestarikan lingkungan.

2. Perlu dirancang suatu sistem pengelolaan sampah secara berkelanjutan dan terintegrasi serta dibangunnya infrastuktur yang memadai untuk mencegah warga membuang sampah di bantaran Sungai Jangkok. Hal ini perlu segera dilakukan melihat terus meningkatnya aktifitas pariwisata di Pulau Lombok. Sistem yang dibangun membutuhkan kerja sama antara pemerintah setempah khususnya Dinas Lingkungan Hidup dan masyarakat setempat agar dapat menjaga keselarasan lingkungan serta mencapai suatu sistem pengelolaan sampah yang berkelanjutan.

3. Perlu diadakan suatu skema pelatihan pengelolaan sampah yang berkelanjutan untuk masyarakat serta sistem pemantauan/monitoring berkala. 
4. Perlu dilakukan riset yang lebih mendalam mengenai proses pengelolaan sampah di berbagai daerah wisata di NTB dan dilakukan pengkajian mengenai praktek terbaik yang sesuai dengan kondisi sosial masyarakat di NTB

\section{Ucapan Terima Kasih}

Ucapan terima kasih disampaikan kepada Bappeda Provinsi NTB dan Dewan Riset Daerah Provinsi NTB atas dukungan selama penyusunan naskah ini dan pihakpihak lain yang sudah bersedia memberikan data dan saran dalam penyusunan naskah ini.

\section{DAFTAR PUSTAKA}

Artiningsih, N. K. A., Hadi, S. P., \& Syafrudin. (2012). PERAN SERTA

MASYARAKAT DALAM

PENGELOLAAN SAMPAH RUMAH

TANGGA (Studi Kasus di Sampangan \& Jomblang, KotaSemarang). Serat Acitya. http://jurnal.untagsmg.ac.id/index.php/sa /article/view/29

BKKBN. (2019). Batasan dan Pengertian $M D K$.

http://aplikasi.bkkbn.go.id/mdk/Batasan MDK.aspx

BPS. (2019). Istilah. https://www.bps.go.id/istilah/index.html ?Istilah_page $=4$

BPS NTB. (2019). Banyaknya Kunjungan Wisatawan ke Provinsi Nusa Tenggara Barat 2009 -2016. https://ntb.bps.go.id/dynamictable/2017/ 06/07/155/banyaknya-kunjunganwisatawan-ke-provinsi-nusa-tenggarabarat-2009---2016.html

Chambers, R. (1994). Paradigm Shifts and the Practice of Participatory Research and Development.

Dewi, R. P. (2017). PERANCANGAN SISTEM PENGELOLAAN SAMPAH UNTUK MENDUKUNG PERKEMBANGAN INDUSTRI KREATIF DI DAERAH PARIWISATA (Issue 3).
Joseph, K. (2006). Stakeholder participation for sustainable waste management. Elsevier. https://www.sciencedirect.com/science/a rticle/pii/S0197397505000524

Lu, J., \& Nepal, S. K. (2009). Sustainable tourism research: An analysis of papers published in the Journal of Sustainable Tourism. In Journal of Sustainable Tourism (Vol. 17, Issue 1, pp. 5-16). https://doi.org/10.1080/09669580802582 480

Putri, I. A. T. E., Mardani, N., \& Pujaastawa, I. (2012). Studi Sistem Pengelolaan Sampah Berbasis Komunitas Adat Di Desa Adat Seminyak Kecamatan Kuta Kabupaten Badung. In Ecotrophic: Journal of Environmental Science (Vol. 5, Issue 1).

Riswan, Rya Sunoko, H., Hadiyarto, A., Kesehatan Kabupaten Hulu Sungai Selatan, D., Selatan, K., Kedokteran, F., Semarang, U., \& Teknik Kimia, F. (2011). PENGELOLAAN SAMPAH RUMAH TANGGA DI KECAMATAN DAHA SELATAN. In Jurnal Ilmu Lingkungan (Vol. 9, Issue 1).

Rodic, L., Scheinberg, A., \& Wilson, D. C. (2010). Comparing Solid Waste Management in the World' s Cities. October, November, 15-18. http://www.sswm.info/sites/default/files/ reference_attachments/UN HABITAT 2010 Solid Waste Management in the Worlds Cities.pdf

Setiadi, A. (2015). Studi Pengelolaan Sampah Berbasis Komunitas pada Kawasan Permukiman Perkotaan di Yogyakarta. Jurnal Wilayah Dan Lingkungan, 3(1), 27. https://doi.org/10.14710/jwl.3.1.2738

Utami, B. D., Indrasti, N. S., \& Dharmawan, A. H. (2008). Pengelolaan Sampah Rumahtangga Berbasis Komunitas: Teladan dari Dua Komunitas di Sleman dan Jakarta Selatan. Sodality - Jurnal Sosiologi Pedesaan, 2(1). https://doi.org/10.22500/sodality.v2i1.58 93 
Visvanathan, C., Visvanathan, C., Adhikari, R., \& Ananth, A. P. (2007). 3R Practices for Municipal Solid Waste Management in Asia Membrane Based Emergency Water Supply View project British Council, Newton Fund, Institutional Links project "Community Scale, Decentralised Anaerobic Digestion for Energy and Resource Recovery" Vi. https://www.researchgate.net/publication /268299500

Vitasurya, V. R. (2017). SAWITRI (Sampah Wisata Pentingsari): Model Pengelolaan Sampah Aktivitas Wisata Desa Pentingsari, Yogyakarta. Jurnal
Arsitektur KOMPOSISI, 10(5), 315. https://doi.org/10.24002/jars.v10i5.1092

Wilson, D. C. (2007). Development drivers for waste management. https://doi.org/10.1177/0734242X07079 149

World Health Organization. (2002). Community participation in local health and sustainable development: A working document on approaches and techniques.

World Tourism Organization. (2004). Indicators of sustainable development for tourism destinations : a guidebook. World Tourism Organization 